\title{
FORO ACTUALIDAD LABORAL
}

(Transcripción)

\author{
ORGANIZADO POR DEPARTAMENTO DEL TRABAJO Y DE LA SEGURIDAD SOCIAL \\ FACULTAD DE DERECHO, UNIVERSIDAD DE CHILE. \\ (ESTE FORO SE LLEVÓ A CABO EL 30 DE MAYO 2011)
}

\section{HÉCTOR HUMERES}

Director del Departamento de Derecho del Trabajo y Seguridad Social

\author{
BRUNO BARANDA \\ Subsecretario del Trabajo
}

Álvaro Fuentealba

Director de la Escuela de Derecho de la Universidad de Chile

OSVALDO ANDRADE

Diputado, ex ministro del Trabajo

Diego Olivares

Presidente de la Unión Nacional de Trabajadores (UNT)

ABRAHAM ARMIJO

Director y tesorero de la Central Autónoma de Trabajadores (CAT)

\section{ANDRÉS CONCHA}

Presidente de la Comisión Laboral de la Confederación de la Producción y del Comercio (CPC) y presidente de la Sociedad de Fomento Fabril (SOFOFA).

\section{NiCOLÁS MONCKEBERG}

Diputado RN

HÉCTOR HUMERES: La dinámica del mundo del trabajo es sumamente profunda y constante y nos obliga a una permanente actualización sobre su quehacer y principales orientaciones. Nos parece que el Departamento de Derecho Laboral y de la Seguridad Social de la Facultad de Derecho de la Universidad de Chile no puede estar ajeno a esta situación, sino que debe estar inmerso en ella y procurar encauzar debates de ideas y visiones acerca de la misma, con una mirada amplia, pluralista y participartiva.

Bajo esa perspectiva, nos ha parecido pertinente la realización de un Foro sobre la Actualidad Laboral de este momento, que permita el intercambio de ideas y pareceres en relación a ella, entre los destacados representante de entidades vinculadas al quehacer laboral del país que hoy día nos acompañan, y a quienes dejo a contar de ahora con el uso de la palabra.

BRUNO BARANDA: Agradezco al Departamento de Derecho del Trabajo de la Universidad de Chile por haber organizado este encuentro en la persona de su director don Héctor 
Humeres. Y también quisiera agradecer y reconocer a todos los que han trabajado para hacer posible este encuentro.

Muchas gracias también a todos ustedes por su participación y, especialmente, a quienes acompañan las presentaciones.

Encuentros como este son tremendamente importantes para nuestro gobierno porque permiten conocer la opinión y experiencia de quienes han venido a participar y compartir algunas reflexiones del gobierno del presidente Piñera; a la vez porque permite también dar cuenta pública sobre lo que hemos hecho durante el primer año del actual gobierno y de lo que estamos haciendo como Ministerio del Trabajo, con la finalidad de alcanzar en el mundo del trabajo chileno los más altos niveles propios de una sociedad justa, culta y moderna.

Al contrario de lo que ha estado sosteniendo un grupo de dirigentes de la oposición, incuestionablemente el gobierno de la Coalición por el Cambio sí tiene un programa de gobierno en materias laborales y de seguridad social, y una clara agenda de trabajo. Tiene un relato, como a algunos les gusta señalar hoy día, preciso y contundente en pleno desarrollo. Y que la misma no se agota ni se limita en modificaciones al Código del Trabajo y que, además, el que no coincida ni represente el interés actual de la Concertación, al debe en materias laborales y de seguridad laboral, no significa que no exista.

La agenda, su realización y la filosofía en que se inspira es el contenido sustancial del nuevo trato para el mundo del trabajo, para el cual el presidente Sebastián Piñera ha convocado a todos los sectores de la ciudadanía, en especial a trabajadores y empleadores.

Implica, por supuesto, modificaciones legales, pero basadas en un cambio de conciencia social, en un cambio de educación y de cultura nacional en el desarrollo de las relaciones laborales y, por sobre todo, en el trato y en las relaciones de la autoridad para con los trabajadores y sus dirigentes.

El Presidente de la República y todos sus colaboradores directos tienen no solo la genuina convicción y voluntad para avanzar en la instalación de una cultura superior en las relaciones laborales colaborativas y constructivas y en el efectivo desarrollo de las buenas prácticas sino, además, el compromiso de hacerlo con la ciudadanía.

El gobierno ha definido como dos cimientos de esta agenda laboral la creación de un millón de empleos, y no cualquiera, sino, en segundo lugar, de buenos y mejores empleos.

Para ello, se han implementado políticas públicas y se han tomado ciertas medidas que, en este primer año de gobierno, han permitido, por ejemplo, una disminución en más de tres puntos de la tasa de cesantía, la creación de miles de empleos, un crecimiento de la demanda del trabajo y también de la oferta al aumentarse la fuerza laboral, un incremento del número de mujeres que está participando en el mundo del trabajo desde el 39.5\% a marzo de 2010 hasta el $42.5 \%$ a marzo de este año.

También empleos de mejor calidad, la extensión y el ejercicio de las buenas prácticas laborales, un acceso efectivo y fácil a la seguridad social, restablecer el valor de la vida y la seguridad de todos los trabajadores por sobre cualquier otro criterio, parámetro o presupuesto.

El pago de remuneraciones razonables y suficientes, las mismas que en los últimos doce meses se han visto incrementadas en una tasa real de más del 5\%.

Respeto a los derechos laborales, tales como la obediencia a los tiempos de descanso, a los tiempos personales, de la familia, etc. 
El nuevo trato, más empleos y de mejor calidad, son los tres primeros propósitos básicos y esenciales de la agenda laboral social del gobierno de la Coalición por el Cambio.

Ello implica también, desde otra perspectiva, implementar otras iniciativas en actual desarrollo o ejecución con que el gobierno está cumpliendo sus compromisos en el área laboral social.

Con trabajadores y empleadores organizados hemos sostenido muchas, y largas e intensas, reuniones de trabajo, bajo la convicción de que el diálogo social permanente es la gran herramienta para producir los cambios culturales que luego deben traducirse en leyes e instrumentos jurídicos.

Para desarrollar seriamente esta responsabilidad y la política del gobierno del presidente Piñera, el Ministerio del Trabajo y Previsión Social ha creado la Unidad de Diálogo Social, de la que dependen áreas tan importantes como las relaciones sindicales gremiales, las escuelas de formación, las mesas de diálogo y, una cuarta, de trabajo y sociedad donde se discute y analiza el tema mujer y trabajo, la mayor inclusión, precisamente, de las mujeres en la oferta laboral, el trabajo infantil, etc.

Una tercera plataforma que compone esta agenda laboral social y da contenido al nuevo trato implica la reestructuración y modernización de diversos servicios del Estado para que se transformen en una herramienta efectiva para una mejor empleabilidad.

La reestructuración del Servicio Nacional de Capacitación y Empleo (SENCE), liderada por la ministra Evelyn Matthei, comprende no solo el aumento de recursos, sino que también sustanciosos cambios que concluirán en una mejor gestión de políticas de intermediación y de capacitación para quienes no tienen empleo, para trabajadores que pueden y desean progresar, y también para pequeños empleadores.

La implementación de programas con mayor pertinencia, focalización y certificación darán paso a mayores competencias y habilidades laborales para los trabajadores.

Todo ello, entonces, aumentará las posibilidades y las expectativas de mejorar los ingresos de las personas y mejorarán, también, la empleabilidad y la productividad.

De igual forma, aspiramos a que la Dirección del Trabajo no solo cumpla sus obligaciones y sea eficaz en la fiscalización del respeto a los derechos y obligaciones laborales. Después de muchos años se acaba de aumentar en más de 60 el número de fiscalizadores en terreno, y además se constituyó en un servicio que permita señalar, divulgar y expandir el ejercicio de las buenas prácticas laborales en el país.

Una reestructuración de esta Dirección es imperativa como lo es también la mayor y mejor capacitación de sus funcionarios y la coordinación de sus unidades, la homologación de criterios de fiscalización y la actuación de los propios fiscalizadores en terreno, la fiscalización asistida, de educación y preventiva, la autoevaluación, el uso extensivo de las herramientas tecnológicas, entre otras medidas.

Por último, el gobierno considera también una agenda legislativa, que le parece fundamental, con el objeto de contribuir, desde la perspectiva del nuevo trato y del programa de gobierno, a la gran meta de constituir a nuestro país en una nación desarrollada al término de la presente década.

Algunos de estos proyectos de ley son el trabajo a distancia, cuyo objeto es regular las relaciones laborales entre un trabajador que se desempeña desde su hogar o desde un lugar libremente elegido por este, lejos del establecimiento del empleador y sin la supervisión 
inmediata y directa del mismo, y que debe constituirse en una puerta de acceso al mercado laboral para un grupo importante de mujeres, personas discapacitadas y jóvenes que hoy enfrentan diversas barreras de acceso a este mercado.

En segundo lugar, el gobierno ha presentado una propuesta concreta para corregir las malas prácticas que implican la utilización de múltiples RUTs, distorsionando abusivamente el concepto de empresa, para socavar el derecho de negociación colectiva sin afectar, a la vez, la libre iniciativa de emprendimiento ni la legitimidad de empleadores que organizan sus negocios en distintas entidades jurídicas por razones diferentes al detrimento de los derechos laborales de los trabajadores.

Un tercer proyecto, conocido como postnatal, es tal vez la reforma más profunda de los últimos 30 años en beneficio de las mujeres trabajadoras. No solo establece la ampliación de 3 a 6 meses del permiso de postnatal, sino que incorpora a este sagrado derecho de protección a la maternidad a un grupo importante de mujeres que hasta hoy estaban legalmente excluidas, como las temporeras, los padres adoptivos de hijos mayores de 6 meses, etc., y otorga ciertas flexibilidades con cuidado y resguardo a la maternidad, entregando a la vez mayores responsabilidades a los padres.

Por su parte, con la eliminación paulatina y la reducción del 7\% de salud para los tres primeros quintiles más pobres y más vulnerables de los pensionados, el gobierno del presidente Piñera está respondiendo a un requerimiento social focalizado en los sectores jubilados más vulnerables y medios o medios bajos.

En seguridad laboral, se inició un trabajo con la suscripción, por parte del gobierno, del convenio 187 de la Organización Internacional del Trabajo (OIT) y su proposición al Congreso Nacional para que se transforme en proyecto de ley.

Se continuó con el trabajo de la Comisión Asesora Presidencial. En un recorrido inédito por el país, durante 90 días sus integrantes recogieron opiniones y aportes para una mejor seguridad en el trabajo. Esta gira concluyó con un informe que fue entregado al Presidente de la República a fines del año pasado.

Luego han venido más de cuatro meses de intenso trabajo en que se instalaron mesas de seguridad laboral en cada una de las intendencias regionales y se ha preparado la redacción de múltiples y profundas reformas legales reglamentarias que implicarán las definiciones del gobierno en orden a subir el estándar de la protección a la vida, a la seguridad y a la salud de los trabajadores y empleadores.

Estamos en marcha y en la ejecución plena de una fecunda agenda laboral social, trabajando activamente para dar vida al nuevo trato laboral en Chile; un nuevo trato que posee no solo contenido y sustancia, sino que mucho relato y una filosofía renovadora de la cultura laboral en nuestra nación.

Y es que al presidente Piñera y a su gobierno los trabajadores le importan, y mucho.

Después de todo, en este gobierno todos somos y nos sentimos trabajadores.

Muchas gracias.

DIEGO OLIVARES: Cuando me invitaron a esta reunión, estaba contento porque me habían confirmado que también venía la otra central sindical. 
¿Por qué digo esto?

¿En qué contexto planteamos la realidad laboral actual? Yo soy dirigente sindical desde hace mucho años, fui también dirigente de la hermana central, de la CUT, en un tiempo en que soñábamos mucho, Eran tiempos muy difíciles en los que aspirábamos a tener muchos trabajadores organizados, muchos trabajadores afiliados y muchos derechos adquiridos por el proceso de la recuperación democrática.

En el año 1993, estando en México ocupando un cargo internacional me tocó presentar un librito que se hizo en Chile de dos profesores destacados de esta universidad: don Reynaldo Sapag Chain, economista, y de don Francisco Walker, destacado jurista laboralista.

Y siendo este un análisis del año 1993, recién recuperada la democracia, de cómo habían crecido los salarios de esos 3 años y de cómo habían crecido los grupos económicos tanto transnacionales como privados. Hablamos de las 100 empresas más grandes. Se hizo una encuesta también entre los trabajadores.

La verdad, era que la diferencia entre lo que se ganó y lo que los trabajadores ganábamos era sideral.

Dieciocho años después uno tendría que preguntarse en qué condiciones estamos.

Y la verdad de las cosas es que estamos con mucho menos sindicalización, con muchas menos organizaciones que tienen derecho a negociar colectivamente. Hoy día, nada más que cerca del 5\% de los trabajadores de este país tienen derecho a la negociación colectiva.

Por lo tanto, cualquier modificación, cualquier cambio en términos de mejores condiciones para la negociación colectiva o de colocar estos temas, no incide mucho respecto de la simetría del poder que existe entre el capital y el trabajo.

Y ahí tenemos el primer problema.

Han pasado varios años de los gobiernos democráticos, incluido este, y uno empieza a ver en estas aulas la misma discusión, la misma conversación.

Y pareciera ser que o no hay voluntad política o hay temor a tocar ciertos temas.

Hoy día, quienes quieren tener un resultado en torno a la negociación colectiva en forma importante son las empresas grandes. Y no son muchas o, más bien, son las que aportan en gran medida al Producto Interno Bruto (PIB), pero que no son muchos los trabajadores que están incluidos en ellas.

Yo, por ejemplo, vengo de una transnacional, del Scotia Bank, un banco de mil trabajadores en Chile y 45 mil en el mundo, y ustedes dirán claro, tiene capacidad de negociación colectiva. Sí, tiene.

¿Mejor que el promedio?

Sí, mejor que el promedio.

Pero ¿qué pasa con el resto de las empresas medianas y pequeñas, y qué hacemos con eso?

La UNT plantea que una verdadera negociación es una negociación por ramas de la producción.

$\mathrm{Y}$ nos responden que eso es imposible porque cada empresa tiene que resolver sus asuntos internamente.

En la mayoría de los países desarrollados que yo conozco, que no son pocos, la verdadera negociación colectiva, la que da poder, la que da un equilibrio entre los poderes, es aquella que se aplica a nivel nacional. 
Usted puede discutir cuáles son las grandes empresas, cuáles son las medianas y cuáles son las pequeñas y fija un piso.

¿Qué pasa con el salario mínimo, por ejemplo? Y vamos a entrar de nuevo en la discusión de todos los años de cuánto es el monto que subimos y si el porcentaje es del tres o del cuatro. Ya escucho montos por ahí, si en realidad un número importante de trabajadores en este país está en grandes empresas.

Pero con ese salario mínimo actual, o el que podemos mejorar en los próximos días, ¿vive una familia en condiciones normales en este país?

¿Hay un equilibrio entre lo que el país ha crecido y se ha desarrollado, que por cierto lo ha hecho y ha avanzado en muchas materias, y la realidad de un número importante de trabajadores en este país?

Hoy día, partiendo por esta audiencia no me cabe duda, la mayoría de los trabajadores somos esclavos de las tarjetas de crédito. Y uno va por ahí a cualquier supermercado, y mayoritariamente en los sectores populares, y ve que la gente compra hasta el pan con la tarjeta.

Vivimos en una sociedad que, francamente, está absolutamente distorsionada.

Yo no digo aquí que haya que quitarles las empresas a los ricos, como hace un tiempo se dijo. Aquí se trata de cómo ponemos el equilibrio para que estas cosas que se prometen se cumplan, pero que se cumplan en serio.

Cuando se dice que se han creado tantos nuevos empleos digo sí, se ha hecho probablemente en este espacio de tiempo. Pero, ¿qué tipo de empleos? Empleos precarios, empleos sin protección social, empleos muchas veces que son por una hora o dos de trabajo.

¿Por qué, entonces, no somos capaces de sentarnos a conversar y a ponernos de acuerdo en lo que queremos como país?

Tenemos un país que está enfermo y yo no quiero ser negativo frente a los análisis exitistas que se hacen respecto del desarrollo. Quiero ser provocador respecto a que nos pongamos de acuerdo.

Aquí hay ciertos temas que no están bien. Hablábamos recién de la negociación colectiva por rama. ¿Cuál es el problema de la negociación colectiva por rama? ¿Por qué se dice que no es posible negociar por rama?

Miren, Francia no tiene más del 5\% de los trabajadores organizados, un porcentaje similar al de Chile. Tiene seis centrales sindicales, como la mayoría de los países de Europa. Salvo en Cuba y en Bolivia, aquí en América Latina hay una sola central sindical.

Pues bien, cuando las centrales sindicales negocian a nivel nacional sí están las condiciones de todos los trabajadores del país. Y ahí está el equilibrio.

¿Y qué hemos hecho para que el sindicato sea un actor de contraparte del mundo del capital?

No ha pasado nada. Por el contrario, sigue habiendo problemas en los sindicatos, También hay sindicalistas, me incluyo, que no hacemos bien la pega. Y eso también hay que decirlo.

Yo creo que una de las cuestiones en que el movimiento sindical está en deuda con la ciudadanía y con el país es en reconocer también nuestros propios errores.

Estamos en un nuevo siglo, estamos en otra era, estamos en otra época; y muchas ve- 
ces los dirigentes sindicales no estamos dando el verdadero golpe a los conflictos y por eso muchos jóvenes, muchas mujeres que hoy día son las que abundan en el mundo del trabajo, no están ni ahí con el sindicato.

También el sindicalismo tiene que dar un salto de profesionalización, de modernización. No se trata de cambiar los principios ni los valores, puesto que ellos hoy día son los mismos por los cuales lucharon Clotario Blest, Luis Emilio Recabarren o Luis Figueroa, quien de presidente de una central llegó a ser ministro de un gobierno. Él también se dio cuenta de que cometió un error.

El movimiento sindical debe ser capaz de provocar los cambios con este gobierno, con el que venga o con el que sea.

El movimiento sindical debe ser capaz también de dar un salto cualitativo en su desarrollo, en su estructura, en sus métodos, en su estilo y en su forma de hacer sindicalismo.

No estamos convocando.

Tenemos todavía, de manera importante, una legislación restrictiva hecha durante el gobierno militar, una legislación desvinculada de la comunidad.

Por cierto, pasaron muchos años de los gobiernos de la Concertación por quienes muchos, por lo menos yo, nos jugamos durante mucho tiempo. Y tampoco avanzamos mucho.

Entonces, el punto se trata de que seamos capaces de mirar el país como una sociedad, como la que queremos para desarrollarlo.

Veamos las universidades y su montonera de carreras. ¿Adónde apuntan? ¿Qué es lo que queremos hacer? Yo levanto una piedra y aflora una universidad.

Los países que han avanzado, mis queridos amigos, han sido los que se han sentado a la mesa y se han imaginado la nación que quieren. Y allí están los trabajadores, los empresarios, los académicos, los partidos políticos. Allí está la sociedad en su conjunto.

Termino diciendo que a este país le falta un gran instrumento que nos convoque a aquello. Está muy de moda el tema del diálogo social. Hoy día, todos hablan del diálogo social. Y yo me acuerdo que Manuel Bustos, mi amigo, me decía Diego, pero si dialogamos y dialogamos y no conseguimos nada, entonces vamos para atrás.

Yo creo lo mismo.

Pero realmente si somos capaces de mirar al diálogo social como un instrumento de desarrollo del país, en que nadie tire del mantel cuando le molestó el que está al frente, donde nadie sea excluido para discutir los temas de país, entonces sí podemos ir avanzando.

En este país, lamentablemente, los casos que se muestran son los negativos. Eso lo podemos ver en la prensa. Hay empresas en donde están establecidas exitosamente las relaciones entre trabajadores y empresarios.

Lo vimos hace unos días, yo también pertenezco a una mesa de diálogo con los empresarios cristianos, en el que pusimos dos casos. El caso de Sodimac, que es una de las empresas con relaciones laborales extraordinarias, con varios sindicatos, con cerca del $80 \%$ de la gente sindicalizada. Tiene todo un estilo moderno.

Y analizamos el caso de otra empresa, con un sindicatito pequeño, a la que le hicimos una huelga grande en el año 1996. Casi quedó destrozada y las relaciones laborales quedaron por el suelo; sin embargo, sobre la base de la confianza y de la generación de acuerdos entre trabajadores y empresarios nos permitieron ir avanzando y mejorando las condiciones 
no solamente en lo referido a relaciones laborales, sino que en las condiciones de vida de los trabajadores.

Bueno, ¿por qué no ponemos eso en perspectiva para las relaciones laborales en nuestro país?

¿Qué es lo que nos falta, qué es lo que tienen los empresarios?

No se trata de ir en contra de nadie. Todos sabemos que hay malos y buenos empresarios.

$\mathrm{Y}$ yo soy de los que sostienen que se ha ido produciendo un cambio importante, por lo menos un cambio de actitud, pero lamentablemente eso no se traslada ni se traspasa a una mayor generación de recursos para los que necesitan más.

Finalmente, quiero decir que en todo lo que me ha tocado vivir desde la recuperación de la democracia siempre he tenido mucha esperanza, creo que se ha avanzado muchísimo.

Pero sí hay un punto que está pendiente y ese es el tema del mundo del trabajo. Creo que ahí todos tenemos responsabilidades y espero que, finalmente, este gobierno cumpla. Igual que todos los gobiernos tiene la mejor de las voluntades, pero miren lo que hay.

¿Qué es lo que ocurre, finalmente, cuando hay que llevar adelante y concretar los grandes acuerdos que permitan mejorar las condiciones de los trabajadores?

Hace cinco años todo el mundo hablaba del salario ético. Hoy volvimos al mismo punto, seguimos discutiendo entre $\$ 170$ mil y $\$ 180$ mil. Pero estábamos hablando en ese tiempo de $\$ 250$ mil a $\$ 280$ mil.

A lo que llamo, más bien, en esta reflexión, es a que hagamos un esfuerzo como país porque, sinceramente, a mí me preocupa y nos preocupa como UNT el estado de avance en que estamos.

Lo que hemos visto en estos días, sin profundizar en lo de Hidroaysén, creo que algo refleja y no vaya a ser cosa que nos entusiasmemos tanto que nos distanciemos de tal manera de los grandes problemas o de las grandes oportunidades que el país tiene y, simplemente, nos las farreemos.

Más allá de los anuncios o de los proyectos de ley que se envían al Parlamento, lo importante es cuántos de ellos finalmente llegan a buen término y favorecen a los que más los necesitan.

Ese es el desafío que tenemos. Y ese es el desafío no solamente de los sindicatos, es el desafío del gobierno, de los empresarios y de toda la sociedad chilena.

De otra manera, la verdad de las cosas es que vamos a ir cayendo en un estado anímico que nos puede llevar a una situación por la que varios países, que tuvieron muchas lucas en sus bolsillos, terminan finalmente con democracias bastante debilitadas y con problemas al interior de sus sociedades de bastante complicación.

Yo los invito a eso y muchas gracias por escucharme.

ABRAHAM ARMIJO: En principio quisiera plantear algunos elementos de juicio como para iniciar la propuesta que trae la Central Autónoma de Trabajadores (CAT).

Debo concebir primero que los elementos de juicio que se mencionan hoy día son bastante añejos, con una vigencia que supera los 20 años, y que naturalmente no han sido abordados en plenitud y, por lo tanto, la propuesta que hace la CAT, si bien es cierto es de 
unidad, de autonomía y de diálogo social, primero para la concreción de esas tres materias debemos tener el principio de unidad, cohesión y cuantitativamente convertirlos en una fuerza capaz de lograr los equilibrios para poder ingresar al diálogo social propiamente tal.

Sería inimaginable hoy día, como decimos muchas veces, establecer un diálogo social, dado que ello en principio consta de tres partes. Estamos hablando de trabajadores, empresarios y de un Estado que lo administre en su momento.

Tenemos a los empresarios que están organizados en diferentes instancias en donde todos tienen una sola voz. Tenemos al gobierno que, en su momento, va a ser facilitador en la medida en que la otra parte se ponga a tono. O sea, estamos hablando de los trabajadores como una organización que como mucho agrupa a un 10\%, y que negocian colectivamente un 5\%. Por lo tanto, desde este momento es imposible, bajo esa condición, que haya un diálogo social.

Pero tenemos que generar las expectativas para lograr llegar a tener una organización de los trabajadores que nos permita convertirnos en una amenaza o, por lo menos, convertirnos en un ente que sea capaz de de poner los temas sobre la mesa y evitar, justamente, que alguien tire del mantel cuando no le guste la propuesta.

Frente a eso, la CAT plantea unidad, autonomía y diálogo social.

Unidad, principio básico para encontrar la fuerza necesaria para alcanzar la justicia social para los trabajadores. Para lograr esa unidad es necesario establecer ciertos estatus básicos y hacer realidad esta necesidad: primero, la conciencia de clases.

La dirigencia y el actual movimiento sindical, y los trabajadores en particular, debemos reconocer y recuperar nuestra condición de trabajador, y desde esta situación actuar en la vida personal, social y laboral.

Una vez que adquiramos e instalemos estos elementos de conciencia podremos colocar en práctica los verdaderos principios del sindicalismo, que son solidaridad, unidad, transparencia, empatía y democracia cívica

Tenemos también que concurrir a la diversidad.

Para lograr una verdadera unidad se debe reconocer la existencia del otro. La unidad se forja en la diversidad. El monopolio del movimiento sindical y de no reconocer que existen otras corrientes de pensamiento y de actuar, en vez de ayudar a la unidad se constituye en una práctica divisionista y dictatorial.

Actuar en conjunto, por lo tanto, es nuestro deber.

Debemos ser fuertes y generosos, lo que nos debiera llevar a la unidad de acción a lo menos. Es decir, actuar en conjunto en aquello que nos une, dejando de lado las legítimas diferencias que podamos tener.

Sobre este principio existen experiencias vigentes en el mundo sindical. La expresión máxima de la unidad internacional es a través de la Confederación Sindical Internacional (CSI) y de las Américas (CSA). En ambas, la CAT ha sido fundadora, siempre pensando en la autonomía.

El actuar del movimiento sindical debe estar enmarcado desde y para los trabajadores. El movimiento sindical debe tener la capacidad, la fuerza y la decisión que desde sus propios y legítimos intereses y con fuerza propia pueda transformarse en un verdadero interlocutor y protagonista del desarrollo de la sociedad y de las políticas que implementan los gobiernos de turno. 
La autonomía no significa aislarse ni despreciar las otras formas de organización de la sociedad en democracia, sino por el contrario, ya que en ciertos instantes se deben crear alianzas. Pero en el bien entendido de que estas se constituyen bajo los intereses de los trabajadores.

El rol de movimiento sindical es transformarse en un interlocutor válido frente a las autoridades y no declararse parte ni opositor de un gobierno de turno.

La fuerza de un movimiento sindical debe ser utilizada para construir todos los caminos para que las propuestas del sindicalismo se hagan realidad.

Compañeros, compañeras, amigos, amigas, estudiantes todos, este es el llamado y el compromiso que asume la CAT. Una vez que el conjunto de la dirigencia y la fuerza trabajadora del país seamos capaces de asumir con responsabilidad y conciencia de clase, podemos exigir al gobierno nuestras legítimas y justas demandas.

Por nuestra parte, seguiremos avanzando en estos tres postulados: unidad, autonomía y diálogo social.

ANDRÉS CONCHA: Cuando uno observa el funcionamiento del sistema laboral en nuestro país, normalmente uno tiende a verlo en perspectiva. Y realmente creo que uno de los elementos más importantes al cual toda sociedad debe ponerle acento para observar qué es lo que sucede ahí es el tema del empleo.

Creo que una de las funciones prioritarias que debe tener un sistema económico es ser capaz de estimular y generar el empleo que requiere la sociedad.

La juventud que va ingresando a la fuerza de trabajo año a año y que espera satisfacer sus expectativas personales y profesionales, obviamente, el trabajo en ese sentido es el instrumento principal para que las personas puedan proyectarse en la vida y realizarse como tales.

Siento que en Chile hemos avanzado muchísimo en esto. Realmente, cuando uno analiza lo que ha ocurrido en los últimos 20 o 30 años en nuestro país observa dos cosas.

Primero, que el empleo ha estado aumentando en forma sistemática en la medida en que ha estado creciendo el producto. El producto, en el fondo, es lo que mide el comportamiento de la actividad productiva año a año.

¿Qué es lo que ha ocurrido en Chile?

En este último período, 25 a 30 años, realmente el crecimiento del producto ha sido casi el doble de lo que fue en los períodos anteriores.

Realmente, en nuestro país hemos vivido una experiencia de cambio de ritmo de crecimiento bastante impresionante.

$\mathrm{Y}$ eso es lo que ha permitido que el empleo en Chile haya aumentado como probablemente nunca ocurrió históricamente en el pasado en nuestro país. Realmente ha habido un aumento, por ejemplo, en la participación laboral de la mujer que partió de niveles que eran los más bajos del mundo. Los niveles de participación laboral de la mujer en Chile eran del orden del 25\%. Hoy día, estamos alcanzando, no conozco las últimas estadísticas, pero creo que niveles del $45 \%$. Eso sigue siendo bajo en el contexto internacional e, incluso, sigue siendo bajo dentro del contexto de América Latina. Probablemente nos deben quedar por lo menos unos 15 puntos de crecimiento de mayor inserción que la mujer debiera tener en el mundo del trabajo. 
En eso vemos que también se están dando pasos para que aquello ocurra. Por ejemplo, el programa de protección a la infancia, que se impulsó en nuestro país desde hace algunos años y que se ha ido perfeccionando con el transcurso del tiempo, gradualmente está permitiendo que las mujeres que normalmente tenían que preocuparse personalmente del cuidado de los niños, hoy día están encontrando mayores alternativas donde poder dejar a sus niños entre las edades de cero a cuatro años y, posteriormente, se pueden incorporar ya a los estudios escolares.

Pero eso, que realmente complementa el sistema de trabajo que la mujer debe realizar en su hogar, especialmente en el cuidado de los niños, es esencial para poder difundir y facilitar la penetración de la mujer en el mundo del trabajo.

Eso está ocurriendo y, creo, en el fondo debiéramos esperar en el curso de los próximos años una mayor participación de la mujer en el mundo del trabajo.

En el tema de la participación del empleo, hoy día estamos viendo en muchas partes, por cifras que nos llegan, que hay escasez de trabajadores. Y eso es muy sano para la economía porque es un estímulo para que las remuneraciones suban.

Cuando vemos las estadísticas de lo que ha pasado en nuestro país, observamos cómo sistemáticamente, en la medida en que ha ido aumentando la productividad, ha ido aumentando la remuneración.

¿Y cómo aumenta la productividad en nuestro país?

Bueno, una parte se gana por una buena formación: formación en el colegio y, por otra parte, la posibilidad de acceder a la educación superior. En todo eso hemos estado avanzando. Hemos avanzado en cobertura escolar y en el aumento de los matriculados en la educación superior.

Pero, en definitiva, creo que en donde más se gana en productividad es en los lugares de trabajo. O sea, realmente, las empresas son las grandes formadoras de habilidades laborales en nuestro país. Una persona que tiene oportunidades puede perfeccionarse en el trabajo que está desarrollando y puede adquirir una habilidad o una destreza que el día de mañana, si tiene que buscar otro trabajo, va a tener la posibilidad de mostrar en su currículo la ganancia de cuáles son sus habilidades.

En Chile creo que también estamos avanzando en un sistema, creo que todos hemos estado de acuerdo en impulsarlo, de poder certificar las competencias laborales.

Esta certificación se puede hacer, uno, por estudios donde como consecuencia del aprendizaje que se realiza especialmente en carreras técnicas, lo que permite posteriormente evaluar cuál es el conocimiento o cuál es la destreza que se ha desarrollado con ese estudio.

Esto está recientemente siendo introducido en nuestro país. Se ha creado una institución que está vinculada a los Ministerios de Educación, Trabajo y Economía y se llama Chile Valores. Allí se están construyendo y tipificando estas habilidades o destrezas que se exigen para cada actividad; de manera tal que las instituciones que imparten las educaciones, ya sean secundaria, técnica, profesional o superior, CPT o institutos profesionales, se puedan guiar por este sistema que permite saber qué es lo que está pidiendo el mercado en cada una de las actividades productivas para que estos establecimientos impartan una instrucción que sea consistente con lo que está necesitando el mundo del trabajo.

Sin embargo, además de eso, se va a poder certificar lo que uno ha aprendido, independientemente de si ha ido o no a estudiar alguna carrera técnica. 
Y por eso, hoy día, para muchas personas que han estado vinculadas con alguna actividad, esto es particularmente importante en ciertas áreas como, por ejemplo, en el mundo de la construcción, en donde un proyecto dura lo que dura la construcción que puede ser un año o un año y medio $y$, posteriormente, hay que ir a otra obra, va constituyendo un aprendizaje que van adquiriendo las personas que están trabajando allí. Y esos aprendizajes, a través de estos sistemas, se van a poder certificar.

¿Por qué hago énfasis en estos aspectos? Que si bien es cierto no están particularmente relacionados con los puntos de los que hablaban antes los presidentes de la CAT y de la UNT, están muy vinculados con lo que ocurre, en general, no solamente en Chile sino que en el mundo entero.

La manera de progresar en términos de ganancia de remuneraciones, fundamentalmente, va a estar definido por la productividad que cada uno de nosotros pueda desarrollar en las actividades que estamos desempeñando.

Hoy el nivel de productividad en promedio que tenemos los chilenos respecto a los países más desarrollados es de un $25 \%$.

¿En qué nos ganan ellos?

Ellos, básicamente, nos han ganado en la formación y en la educación que se ha impartido o que ellos recibieron cuando fueron estudiantes y, posteriormente, en la posibilidad que tuvieron de poder acceder a una formación técnica en instituciones de educación superior.

Eso, realmente, ha permitido a muchos países ir formando gente con atributos que les permite el día de mañana poder manejarse y familiarizarse con estructuras productivas que son más complejas, que son más tecnológicas y que exigen de todos nosotros mayores conocimientos.

En Chile, de alguna manera, eso lo estamos viendo. Yo creo que ha habido un desarrollo tecnológico importante que ha ocurrido en muchas empresas, particularmente vinculadas con los sectores más dinámicos de nuestra economía, como son, por ejemplo, la minería, la energía y, por qué no decirlo también, sectores de la industria del sector forestal o del sector agroindustrial.

También en la pesca estamos viendo actividades que están recién emergiendo y, además, estamos viendo actividades que son bastante más sofisticadas en el sistema financiero y en el retail.

En fin, yo creo que en todos esos lugares estamos observando que en la medida en que esas personas pueden adquirir niveles de productividad más altos y familiarizarse con el manejo de nuevas tecnologías que, como nosotros muy bien sabemos, están siendo materias de un avance dinámico en el mundo entero. Estamos muy rezagados en cuanto a poder participar en todo ese desarrollo.

Pero no estamos rezagados para poderlas importar al país y poderlas incorporar a las actividades productivas que más se requieren para hacerlas competitivas en los mercados internacionales.

Pues bien, la gente que está vinculada con esas actividades realmente puede adquirir las destrezas para manejar de mejor manera todas estas complejidades del mundo moderno. Eso permite potenciar la productividad y, con ello, los rendimientos y las capacidades que tienen las empresas para pagar mejor a sus trabajadores. 
Nosotros hoy día tenemos en Chile una gran asimetría. Yo creo que, como decía Diego, hay empresas grandes, medianas y chicas. Efectivamente, tenemos muchas empresas grandes que han podido generar condiciones para establecer procesos productivos que sean altamente competitivos, y eso nos ha permitido, ya sea competir en los mercados internacionales, ya sea como exportador o bien localmente en Chile compitiendo contra los productos importados o contra terceros, inversionistas extranjeros que quieran establecerse en nuestro país.

En esas entidades, en la práctica, nosotros observamos que hoy día, en general, sin perjuicio de que siempre se va señalar que en tal empresa hubo un conflicto, creo que los niveles de capacitación son mejores para que los espacios para construir climas laborales sean buenos.

¿Por qué?

Porque realmente han podido construir una competitividad que les permite ganar en estabilidad. Y al ganar estabilidad, las condiciones para poder traspasar a los trabajadores, o a quienes trabajan en ellas, mejores capacidades hacen que entremos en un círculo virtuoso, son más estables, son más productivas y tienen más recursos. Esto permite preparar mejor a su gente y potenciar a la empresa.

En este sentido, tenemos muchos casos, como el de Sodimac que mencionaba Diego, que son modelos que debemos difundirlos lo más posible y que se vaya internalizando en todo el tejido empresarial de nuestro país.

Pero por de pronto, hay ciertas condiciones que son esenciales. Las empresas tienen que ser productivas para poder competir contra terceros que sí lo están haciendo.

Nosotros estamos en el mundo global, integrados con el resto del planeta, tenemos relaciones cada vez más fuertes con los países asiáticos. Tenemos los productos chinos y de todos los países del Asia que nosotros compramos en el comercio. Y, por lo tanto, nuestras actividades productivas que se desarrollan en Chile tienen necesariamente que ser capaces de poder enfrentarse no solamente a los países asiáticos, sino que también a la competencia del resto de los países de nuestra región y también de las naciones del mundo desarrollado. Esa es la realidad que estamos viviendo.

Por eso nosotros pensamos que uno de los grandes problemas que tenemos por delante va a seguir siendo la educación, la formación técnica y la formación a lo largo de toda la vida. Eso es un parámetro del cual no podemos olvidarnos porque sin ello nos va a ser muy difícil poder garantizar que nuestros emprendimientos tengan la estabilidad que se necesita para poder generar un clima de trabajo como el que todos queremos. Es decir, que no solamente sea rentable desde el punto de vista profesional que la persona tiene, sino que también permita a cada uno contribuir con su trabajo a hacer un mayor desarrollo personal a lo largo de la vida.

Creo que este es el tema principal y perdonen que no haya entrado en los temas específicos laborales que trataron los señores dirigentes de los sindicatos, pero pensamos que el tema prioritario, como el recurso humano, lo tenemos que enfrentar hacia adelante y van a seguir siendo el tema del empleo y el tema del capital humano.

OSVALDO ANDRADE: A mí me han invitado para que conversemos sobre la agenda laboral. Pero como uno no puede ir en contra de su naturaleza, permítanme unos comentarios previos que tienen que ver con la intervención del gobierno a través del subsecretario. 
Yo estoy muy contento de escuchar que existe una agenda laboral del gobierno y que es contundente. De algo sirve y sería bueno conocerla. En este primer año no la hemos conocido. Hemos hecho un esfuerzo, créanme.

Porque si la agenda laboral del gobierno es la creación de tantos miles de empleo, solo quiero recordar que buena parte de los trabajadores de Chile, los asalariados, son pobres; y que si eso es suficiente y congratula al gobierno, creo que es un exiguo triunfo que puede mostrar.

En este primer año de gobierno hemos conocido y aprobado un proyecto de seguridad social para facilitar el acceso al pilar solidario, hemos conocido un proyecto en materia de seguro de cesantía y hemos conocido un proyecto de prórroga del precontrato.

No hemos conocido más.

Efectivamente, tenemos en discusión un proyecto de teletrabajo, trabajo a distancia, pero quiero contarles que hace más de cuatro meses que estamos esperando la indicación del gobierno para poder tramitarlo, toda vez que el propio Ejecutivo se dio cuenta de que era un error separar el teletrabajo porque teníamos fundadas aprensiones a un retorno a la maquila.

Cosa extraña ante la propuesta de un parlamentario de que se incorporara al sector público el teletrabajo, cuestión que es de suyo evidente. Finalmente lo aprobamos y el gobierno tuvo una serie de dudas. Y digo dudas porque me he puesto un poco elegante esta semana en mi lenguaje, así es que digo solo dudas.

$Y$ en el proyecto del pre y postnatal quiero decirles que si alguna vez los estudiantes de derecho de la Universidad de Chile quieren saber cómo se tramita de la peor manera un proyecto, vayan al Senado para saber cómo se abordó el proyecto del pre y postnatal. Es de manual.

Hemos sido informados hoy día que el gobierno va a recurrir al Tribunal Constitucional por el tema del tope. Vamos a ver qué nos dice. Es interesante cómo se judicializan las iniciativas legislativas.

Es de manual, acuérdense de lo que yo les digo. Profesor, lleve a los alumnos al Senado para que aprendan cómo no se debe tramitar un proyecto tan importante.

Yo concuerdo con el gobierno en que la modernización de la Dirección del Trabajo, el cambio al sistema de la capacitación permanente de los trabajadores y las iniciativas de la seguridad laboral son, sin lugar a dudas, cuestiones en las que tenemos que llegar a grandes acuerdos, y suscribo plenamente el interés que hay por avanzar en eso.

Pero, con la misma franqueza, quiero decir que una auténtica reforma laboral con una auténtica agenda laboral tiene que hacerse cargo de un nudo que es central: tenemos una gran desconfianza en el mundo del trabajo. Sin enfrentar la crisis de confianza es muy difícil avanzar en una agenda laboral sustantiva.

Yo propondría, en consecuencia, que nos hiciéramos cargo de este problema porque como tenemos la sociedad desigual, ya entraremos en la discusión de qué se hizo en estos últimos 20 años. Dejemos para otro día eso.

Pero tenemos desigualdades sociales evidentes.

Enfrentar en un contexto de desigualdad social la crisis de confianza es muy difícil y requiere de un esfuerzo enorme. 
Y hay solo un mecanismo para eso: la conversación y el diálogo. No hay otro porque las otras son las vías de hecho y eso no le hace bien a Chile y a nosotros.

Entonces, la institucionalización del diálogo, la conversación en materia laboral, es el núcleo de cualquier agenda sustantiva.

Si no nos hacemos cargo de eso, todo lo demás son remedios laterales. Y eso significa, en primer lugar, que hay que establecer a los actores reales y concernientes del diálogo. Y esos son los trabajadores y sus sindicatos, los empleadores y sus organizaciones, pero en simetría y equilibrio, porque de lo contrario no se genera el vínculo de la confianza.

Y para eso hay muchas cosas que construir. Hay que empezar por destruir el viejo prejuicio de que todos los dirigentes sindicales son la expresión de Satanás en la tierra y que todos los empleadores son unos chupasangres; porque no lo son ni lo uno ni lo otro. De pronto uno puede tener algunas dudas, pero no lo sé.

Si no destruimos ese prejuicio, no vamos a poder establecer la confianza. Y para generar las confianzas hay que establecer a los actores.

Y, entonces, el problema del multirrut no es un problema vinculado con la negociación colectiva. Es un problema de hacer realidad cuál y qué es la empresa con la cual hay que conversar.

Y no tiene que ver también con derechos colectivos, porque también se transgreden derechos individuales como la gratificación y las salas cunas por la vía del multirrut.

INTERVENCIÓN DE OTRO PARTICIPANTE: También el derecho a huelga...

OSVALDO ANDRADE: Lo tengo más adelante, así es que se va a disculpar conmigo.

Entonces, es un tema básico porque el trabajador quiere saber con quién conversa. Y eso es sano porque cuando está el grupo del multirrut y cuando el Unimarc que está en la esquina es distinto del Unimarc que está en la otra esquina, claro que se produce el problema de la desconfianza porque es obvio.

Entonces, este problema de los multirrut no es solo de la negociación colectiva, es un problema de justicia, de establecer una relación adecuada de confianza.

Y en la misma línea está la sindicalización automática.

Se dice que atenta contra la libertad, bueno y en cuántas cosas atentamos en contra de la libertad, o cuando hicimos el proceso de licitación respecto a la AFP más barata, ¿no estamos afectando la libertad de los cotizantes? ¿O cuándo alguno de ustedes que trabaja puede cotizar en un sistema que no sea la AFP?

¿Y dónde están las libertades? Entonces hagámonos cargo, pues.

Y establezcamos la negociación colectiva y el derecho a huelga. Y esto es básico porque mientras los trabajadores no sientan que no están premunidos de una auténtica base instrumental para hablar simétricamente con la empresa, es evidente que la desconfianza seguirá existiendo.

Y cuando uno conversa sobre las confianzas, perdóneme el castellano castizo, uno está pensando bueno, ¿por dónde me van a afilar?

Entonces ese es el punto. 
Y si vamos a establecer una verdadera negociación colectiva, hagámonos cargo de los problemas que tenemos y entonces digamos negociación colectiva y derecho a huelga en las empresas públicas y privadas. Y si hay problemas de productividad, que sean materias de la conversación de la negociación colectiva. Entonces, si hay problemas con la jornada, que lo aprueben en la negociación colectiva.

Discúlpenme, en el gobierno de la administración anterior uno de los proyectos más importantes que se dictaron, ha tenido poca difusión y nadie cacha mucho, pero en mi opinión fue el más importante, ¿y saben qué se acordó? Que los trabajadores que salen en las lanchas a pescar, en donde zarpas de un lugar y recalas en otro, pueden negociar su jornada con su empleador. El sindicato se pone de acuerdo con su empleador. ¿Qué es eso si no es una negociación por la vía de ampliación de materia? Así lo aprobamos en la ley y hoy día hacemos tanta dificultad por la ampliación de materias.

Pero esto también nos lleva a lo otro, porque si vamos a ampliar las materias, que es algo que tanto les importa a los empleadores para mejorar la productividad, que las jornadas se hagan cargo de mejorar lo otro.

También hablemos de la otra parte. Entonces que no haya reemplazo en las huelgas, que no haya descuelgue, que no haya polizontes, que haya un piso de negociación porque esto no puede ser para un puro lado.

No ven que la desconfianza tiene un significado muy nítido en Chile: está mal pelado el chancho. Perdónenme, yo vengo de la Universidad Católica así es que ustedes comprenderán que el lenguaje que empleo no es el de esta prestigiosa universidad, probablemente.

Entonces, si vamos a avanzar en una parte, avancemos en la otra también. Y avancemos en cobertura. Como bien decía un dirigente aquí, ¿cuántos negocian colectivamente? Repocos. Y vaya que en este país podrían negociar hartos. Y, además, en este país se produce una atrocidad tremenda. Fíjense que en el servicio público no pueden negociar en las empresas matrices y sí pueden negociar en las contratistas, ¿y quién ejerce la ejecución de obras concretas? Las contratistas. O sea, las que pueden poner en riesgo la continuidad del servicio pueden negociar y tienen derecho a huelga. Las otras no lo pueden hacer.

$¿$ No les parece esto una tontera?

Y, además, terminemos con estos cinismos. Ocurre que aquí no puede haber negociación supraempresas. Todos nos negamos a ella, ¿y qué pasa en la realidad?

Cuando se produjo el problema de las forestales, que terminaron con la vida de Rodrigo Cisternas y otros trabajadores heridos, ¿qué hizo la empresa de al lado? La otra grande, ¿qué hizo? Sentó a los trabajadores, a sus dirigentes, con las empresas contratistas y la empresa matriz, la empresa principal, hizo un proceso de negociación supraempresa que terminó en un papel firmado. ¿Qué es eso en doctrina? ¿Y que pasó con los basureros en Santiago, cuando se llenaron de basura las calles? El gobierno sentó a los municipios, a las empresas licitadas y a los trabajadores. ¿Y el gobierno qué hizo? ¿Qué hizo en doctrina? Interempresa, supraempresa y regional, además. ¿Y qué pasa con el Siname? Hace 15 años que el Siname negocia en Chile supraempresa. Tienen conseguido tres sábados y mes. La empresa extranjera que llega y se instala ya tiene tres sábados al mes. ¿Y eso es qué negociación?

O sea, hasta cuándo seguimos negando la realidad. Sí, estas cosas pasan en Chile, yo no vengo a hablar de otro país. 
¿Y en el sector público? ¿En qué parte de la ley está autorizada la negociación colectiva en el sector público? ¿Qué pasa en la realidad? Tenemos paro de advertencia, paro de calentamiento y otros más, y póngale. Todos los años pasa lo mismo, ¿y dónde está en la ley eso?

¿Hasta cuándo seguimos negando la realidad?

Entonces, si esto pasa por la vía de los hechos, ¡cuidado! A lo mejor la invitación es que se sigan haciendo las cosas por la vía de los hechos. Y eso es un problema. Por eso hay que regular e institucionalizar esta conversación y este diálogo.

¿Y en qué consiste esto? En que tenemos que tener la capacidad de ponernos de acuerdo. Si ya nos hemos puesto de acuerdo en tantas cosas, pero para eso hay que expresar si hay voluntad.

Si el gobierno entiende que la agenda laboral es solamente la agenda del empleo, tenemos un problema con eso.

Si el empresariado entiende que solo tiene que ver esto con mejorar la productividad y que se eduquen más los trabajadores, tenemos un problema de voluntad; porque esas cosas son importantes, pero no nos hacemos cargo de núcleo del problema.

Y después se necesitan gestos concretos. Yo invito al gobierno a hacer gestos concretos, convóquenos a un diálogo suprasocial sustantivo, pero de este tema. De cómo mejoramos productividad en una empresa y llevamos a los viejos en la parada.

Como los trabajadores entienden que a la empresa le debe ir bien, pero que a uno también le va bien en ese esfuerzo, entonces hablemos también de gratificaciones. Sí pues amigos míos. Nadie habla de estas cosas. Además, como ustedes saben, como ahora se puede vivir con multirrut, la empresa que tiene grandes utilidades tiene poco personal y la que tiene poca o nula productividad tiene concentrado todo el recurso humano. ¡Mire que novedad! Claro, en una hay gratificaciones y en la otra no.

Gestos. El gobierno tiene que convocar estos gestos. Y, créanme, lo digo con toda franqueza, vamos a estar todos dispuestos a ello porque esta es una cuestión sustantiva.

Y también el empresariado tiene que hacer un gesto.

¿No les resulta a ustedes un tanto patético que la ministra del Trabajo, la señora Evelyn Matthei, le tenga que estar pidiendo al empresariado que condene a Errázuriz? Pero si es de Ripley, si los empresarios saben cuáles son los que se portan mal, ¿y por qué no lo dicen? ¿No creen que sería un gesto tremendamente bueno para construir confianzas que de repente la Sofofa o la CPC digan estos empresarios no cumplen con la ley? Vaya que cambiaría la cosa, y no necesitan hacer una gran pesquisa para saberlo. ¿Y qué cuesta decirlo?

Y, por cierto, ahora también hay una interpelación a esto que se ha dado por llamar, clase política. Cuanto se habla de clases en Chile, ahora se inventó la clase política. También los políticos tenemos que estar a la altura de este desafío. Y, créanme, que el gobierno y la oposición, en el oficialismo y en la oposición, hay voluntad para esto, se los puedo garantizar porque estos son temas que se conversan cotidianamente.

¿Cuál es el desafío entonces?

Primero, evitar el riesgo de las vías de hecho. No puede instalarse la lógica en Chile, y perdónenme por decirlo así, que yo primero me mando una cagada y después converso. Eso es nefasto.

Cuando los trabajadores contratistas del cobre, y particularmente de El Teniente, quemaron las 11 micros fue el peor momento de su negociación, porque perdieron toda su 
legitimidad. Se dieron cuenta que no es por la vía de los hechos por donde se establecen mejores condiciones de negociación. No es posible que para iniciar una conversación me tengo que mandar primero una embarrada. Eso no está en la historia del movimiento sindical. No debemos estimular eso; y para no estimularlo hay que institucionalizarlo, hay que dar confianza para que la gente se sienta llamada a involucrarse en el proceso de negociación. Y para eso hay que darle institucionalidad. Perdónenme, aquí y en todo el mundo se llama negociación colectiva con auténtico derecho a huelga.

$\mathrm{Y}$ en tercer lugar, hay que dar certeza a la negociación, y eso significa una cosa muy concreta hay que darle poder a los involucrados. Miren, yo creo cada vez menos en el tripartismo. Se los dice un socialista. Yo creo que el Estado tiene poco que ver en esto. Hoy día es necesario porque hay que ordenar la cancha, pero en la perspectiva del futuro debieran tener los sindicatos y los empresarios poder suficiente para negociar directamente, sin necesidad de que papá Estado intervenga.

Es algo que hay que lograr y, en el camino, probablemente el Estado y los gobiernos tendrán mucho que decir.

Pero hacia allá debemos apuntar. Los países modernos, a los que se refieren los otros interventores, son aquellos en que los trabajadores con los empleadores tienen amplias negociaciones.

En mi empleo anterior, y con esto termino, se me dijo que Dinamarca era el modelo a seguir, un modelo de seguridad.

Y yo me acuerdo que cuando pregunté cuál era la novedad de allí, era que en Dinamarca negocia el 90\% de los trabajadores. El Estado no se mete. En ese país, además, creo que no hay salario mínimo, no es necesario porque se negocia,

Hacia allá debiéramos ir.

Muchas Gracias.

NICOLÁS MONCKEBERG: Tengo la tentación de cambiar lo que tenía pensado y tratar de decirle a Osvaldo Andrade que tú me acusas de que este gobierno de un año no tiene agenda, sin embargo tú me expones tu agenda y yo quisiera preguntarte por qué en 20 años no la conocimos, ¿por qué todas esas propuestas que aparecen tan bonitas hoy día nunca las conocimos?

Había mayoría en ambas cámaras, pero bueno, no quiero caer en eso porque precisamente mi punto, ese inmovilismo, es el que hoy día me complica. Es que al final los prejuicios y las desconfianzas recíprocas son las que nos impiden avanzar.

Y quiero intentar salir algunos metros de altura y analizar esto con perspectiva, porque tampoco me siento cómodo diciéndoles que estamos en un gran momento. Estamos creando 450 mil empleos al año, más que el promedio de los últimos 20 años, estamos en la curva ascendente de productividad, pero tampoco me siento bien con esto. Son cifras verdaderas, son ciertas, estamos todos contentos, pero no está ahí, siento yo, el verdadero talón de Aquiles de nuestro mercado laboral.

Y a veces siento que, más allá de los años anteriores, nos hemos centrado mes a mes en ver como subíamos las cifras de empleo. Es cierto, es importante, no le resto importancia y uno se da cuenta cuando es parlamentario del drama de la cesantía en una familia. 
Pero el problema de fondo, al que a veces no le prestamos atención, es lo que aquí se llama la bajísima participación que tiene en el mercado del trabajo nuestro país. Porque esto sí que está asociado con la pobreza.

Un país como Chile, que algunos economistas han llegado a decir esta semana que estamos en pleno empleo, tiene una participación laboral bajísima. Y, lo que es peor, está totalmente estratificada.

¿Qué significa esto? Que precisamente el quintil más pobre, la gente con más dificultades es la que menos participa en el mercado laboral. Es una tasa bajísima, ya les voy a dar algunas cifras.

Bueno, pero este tema de la baja participación de nuestro país en el mercado laboral sí que nos hace famosos en el mundo, porque el año antepasado todos celebramos la noticia cuando el último ministro de Hacienda nos anunciaba con gran bombo y platillo que Chile ingresaba a la OSD, grupo privilegiado. Todos nos sentimos orgullosos, sin duda era un avance.

Bueno, pero si nos comparamos con ese grupo, en el ámbito de las mujeres Chile tiene una baja participación de 16 puntos menos que el promedio de los países que están en la OSD. Y si nos vamos a Latinoamérica, la participación de la mujer en el mercado laboral es nueve puntos menos que en el promedio de América Latina.

Si nos vamos al sector de los jóvenes, ¿qué sabemos de los jóvenes? Que tenemos un desempleo bastante alto que es el doble al promedio del desempleo nacional, pero además tenemos una bajísima tasa de participación: 15 puntos menos si lo comparamos con la OSD y 12 puntos menos si nos comparamos con América Latina.

Y la proporción de las personas que participan en el mercado laboral en Chile no ha cambiado en los últimos 20 años. Está congelada, no hemos sido capaces de avanzar un solo punto.

Claro, lo decía Andrés, hemos subido en la participación de las mujeres en el mercado del trabajo, pero lo hemos compensado con una reducción importante de los puestos de trabajo menos calificado y, por tanto, el nivel de participación sigue siendo bajísimo.

Y es ahí, creo yo, un punto que no lo he visto en el debate ni legislativo, ni ahora, ni ayer ni probablemente en las últimas décadas. No está ahí puesta la verdadera urgencia. Insisto, nos quedamos mucho en la tasa de empleabilidad y en los niveles de crecimiento del empleo.

Todos sabemos lo estática que está la productividad, pero no nos hemos sentado legislativamente a buscar las causas y cómo enfrentar esta baja participación en el mercado del trabajo.

Yo les decía que esto es importante porque no es para que un par de economistas de esta universidad o de otra hagan sus papers y se hagan famosos o postulen a algún premio internacional.

No, aquí esta la verdadera razón de la desigualdad social en Chile. Porque, por ejemplo, si nos vamos al quintil más pobre, el más necesitado, en el año 1990, tenía una participación laboral de 32,9\%. En el año 2009, es decir, han pasado más de 20 años, y en el quintil más pobre bajó al $27 \%$

O sea, ni siquiera fuimos capaces de mantener. Por de pronto no subimos nada, sino que bajamos. 
Si nos vamos al quintil más rico en el mismo período, en el año 1990 era del 50\% la tasa de participación en el mercado laboral. En el año 2009 subió a 66\%.

¿Por qué nos sorprende entonces cuando nos dicen que Chile es un país muy desigual? Aquí está lo que verdaderamente afecta y lo que a veces dificulta romper esa brecha entre ricos y pobres.

Tenemos, sin duda, un mercado laboral fragmentado. Y cuando digo fragmentado es porque vemos que en cierta forma, el mismo Código del Trabajo protege muchísimo a algunos trabajadores, pero definitivamente es letra muerta en los hechos para un grupo importante.

Algunas cifras que yo sé que ustedes las deben conocer. El número de contratos de trabajadores en Chile ha caído desde 1994 de un 81\% al 67\% en el año 2009.

Si nos vamos, por ejemplo, a los datos que nos entrega el seguro de cesantía, solo un $63 \%$ de los cotizantes tiene un contrato indefinido.

Un 78\% de los asalariados en Chile ha firmado un contrato de trabajo. La informalidad no ha cambiado en los últimos 20 años.

Y, por lo tanto, a veces uno dice esta dicotomía, esta fragmentación donde para algunos las normas son muy protectoras, pero para otros no existen. Y yo creo que ahí hay un tema verdaderamente importante que nosotros tenemos que ver.

Y, tal como les decía, no siento que en esto esté puesta la verdadera urgencia.

¿Y dónde está el verdadero debate? Uno ve con desazón que por un sector se dice mire, mientras no tengamos sindicalización automática no vamos a superar la desconfianza que existe. Y ahí está la piedra angular para que podamos avanzar en cualquier negociación. Y hay otros que dicen no, mientras no termine el sistema injusto de la indemnización por años de servicio no me vengan a hablar de ninguna sindicalización automática. Y así nos pasamos meses.

Les estoy graficando dos aspectos que yo veo todos los días que parecen ser como el alma máter de los dos sectores, izquierda y derecha, como se le quiera llamar, y caemos en un inmovilismo absurdo.

Yo no estoy diciendo que a veces esta desconfianza o este bloqueo recíproco que, por supuesto, como decía Osvaldo, se produce porque el sector empresarial tiende a ver cualquier movimiento sindical como una amenaza, o el sector sindical tiende a ver cualquier espacio de mayor libertad a la dirigencia de la empresa como una precarización del empleo. Se produce un bloqueo recíproco y no avanzamos nada.

¿Y cómo ha respondido el mundo político? Quizás con lo mismo y escuchamos a muchas personas de izquierda decir que si no les dan sindicalización automática, no avanzamos un metro. Y si no me quitan la indemnización por años de servicio tampoco avanzo un metro.

Y lo que es dramático, voy a hacer una confesión, esto que se dice afuera no se piensa para adentro. Yo he estado con dirigentes sindicales cercanos al mundo más de izquierda y me dicen que al final me encuentran razón. Es malo el sistema de indemnización por años de servicio que tenemos en Chile, pero yo no puedo hacerlo público. Y ese mismo doble discurso, entre lo privado y lo público, también se ve en ambos sectores. No estoy diciendo que sea un discurso de un sector, por lo tanto, creo que estamos en el peor de los mundos.

Tenemos claro el diagnóstico, todos coincidimos en muchas cosas que se han dicho, pero hay una cierta atadura de manos que nos está impidiendo avanzar con realismo. 
Por eso yo partí diciendo que no voy a caer en la tentación de preguntar por qué no se ha hecho nada en todo este tiempo o decir que ahora no hay agenda porque eso entorpece la discusión.

Y, desde ese punto de vista, yo creo que nuestro país tiene que cuestionarse. Y que cuando entremos, por ejemplo, a discutir sobre la sindicalización automática no haya dramas.

Pero vamos al tema de fondo. ¿Qué queremos lograr? ¿Adónde queremos apuntar? ¿Cuál es el objetivo? ¿Quién se ha cuestionado porque en nuestro país las tasas de sindicalización han caído o al menos no han subido? ¿Cuánto de eso hay por prácticas antisindicales, que por supuesto tienen que haber? ¿Pero cuánto de eso es por la falta de interés del mundo de los trabajadores? ¿Cuánto es por mala calidad de algunos sindicatos? ¿Cuánto de eso es por falta de facultades de algunos sindicatos a realmente negociar con poder?

Yo creo que ese debate no se hace. Y se asume casi como una verdad revelada que si realmente se aprueba una ley que diga que el trabajador que ingresa a una empresa es parte del sindicato y que después podría renunciar y con eso se soluciona el problema. Yo no creo en eso.

Como tampoco creo, y voy a ser reiterativo, en un sistema de indemnización por años de servicio a todo evento que acaba con todo el problema de la movilidad laboral. No, no es así. Por supuesto que ha faltado el porqué de todas estas posturas tan ideologizadas.

Y hay una realidad que es indesmentible: hoy día un contrato indefinido promedio dura en Chile 10 meses. Y de esa realidad nuestra legislación laboral no se hace cargo. Nuestro Código del Trabajo no fue hecho para un nivel así de movilidad. No estoy diciendo que sea bueno o que sea malo, solo estoy constatando un hecho real. Hoy día los contratos indefinidos promedio no duran más que eso y, por lo tanto, cuando uno conoce esa realidad es cuando empieza a pensar mire, y que esto no implique una desprotección ni una postura ideológica, pero a veces siento que no nos hemos gastado la suficiente atención en proteger al trabajador, no solo de la estabilidad en el empleo, sino que también de protegerlo en la movilidad del empleo que es propia de las economías no solo de Chile sino que de todo el mundo.

Y tenemos un seguro de cesantía que caer en él es prácticamente como si fuéramos a un abismo. Todos saben que no es lo que uno espera para los tiempos de cesantía.

$\mathrm{Y}$, sin embargo, tenemos un sistema de indemnización por años de servicio que lejos de incentivar la movilidad la dificulta, la entorpece.

Pero a veces siento que en lugar de partir constatando la realidad queremos cambiar todo con un par de normas que, finalmente, no cambian nada.

Yo creo también que ha ayudado mucho la agilización de los procesos laborales, lo digo para que no crean que no se reconocer las cosas buenas, tales como la reforma al sistema judicial laboral. En esta misma universidad he estado en más de 20 seminarios en aspectos laborales en que se ha dicho, puchas, en algunas regiones han sido muy poco rigurosas y los jueces, con tal de darle más agilidad a los juicios llegan a cualquier transacción. Está bien, pero nadie duda hoy en día que la indefensión que había en el mundo del trabajo a la hora de poner un reclamo o interponer una demanda se ha reducido. Y eso, obviamente, va creando espacios para ir avanzando después en el camino de las libertades al interior de la empresa.

Creo, también, que ayudaría mucho hacer una defensoría laboral con nombre y apellido. No puede ser que hoy día cualquier delincuente en este país tiene asegurada una defensa gratuita a través de la Corporación de Asistencia Judicial o, por último, a través de 
la Defensoría Penal, y que un trabajador vulnerado en sus derechos laborales no lo tenga y, en su lugar, tiene que recurrir a un servicio bastante pequeño y de poco impacto como es la defensoría que se hizo hace algunos años.

Yo creo, de verdad, que ayudaría a generar la confianza.

Y, por último, hay ciertas cosas que se pueden hacer. Yo tengo un matiz de diferencia con Osvaldo. Yo creo que hoy día sí están preparadas muchas empresas para avanzar en autonomía.

Cuando él ponía el ejemplo, un buen ejemplo, de los marinos mercantes que se hizo con la actual legislación, lo mismo se hizo con los trabajadores del transporte. Ellos tuvieron la libertad con un sindicato organizado que fue capaz de llegar a un acuerdo de jornadas perfectamente posibles al interior de la empresa. ¿Por qué no replicar ese ejemplo?

Ahí hay dos botones de muestra para que ustedes se tienten y queden con gustito a poco. Porque ahora si quieren un tercer ejemplo tiene que ser con sindicalización automática, está bien. No me niego a que discutamos ese tema, pero ¿por qué deben tener hoy día autonomía en aquellas empresas que ya tienen sindicatos? Eso, con un artículo de dos normas, se podría hacer. Sindicatos que hoy día podrían pactar una jornada más adaptable a la realidad de ellos o, por ejemplo, a la realidad de las mujeres. Yo estoy seguro que muchos sindicatos se tomarían la palabra altiro y llegarían a acuerdos de mejoras de jornada, pero los tratamos como si no tuviesen la facultad de hacerlo.

Yo creo que, independientemente de los temas más duros políticamente, donde hay desconfianzas, hay que preparar la cancha para que algunas empresas, especialmente aquellas que tengan sindicatos en su interior, puedan avanzar. Y yo creo que en eso hemos perdido mucho tiempo.

La jornada flexible de 45 horas a la semana, francamente, me parece que es obsoleto no solo en Chile sino que en el mundo. Son jornadas que hoy día no se adaptan al mundo laboral del que estamos hablando. Y esto no significa que a veces una jornada se haga para que nunca más se pague una hora extra. No, es perfectamente posible y no hemos descubierto la pólvora en que se den más herramientas de las que ya existen y que vayan en beneficio de uno o de ambos. Creo que actuar con escepticismo es un error. Yo creo que hoy día los sindicatos pueden avanzar en esta nueva etapa.

Yo insisto en que los sindicatos sean los que encabecen este tipo de negociaciones desde la empresa. Y le doy una importancia gigantesca al proceso modernizador que está llevando a cabo el gobierno en materia de capacitación porque aquí, lamentablemente, tenemos un sistema evaluado por distintos actores. Políticamente, socialmente y técnicamente todos coinciden en que nuestro sistema actual, en general, salvo excepciones de capacitaciones y de preparación de nuestro recurso humano, es malo y hay que cambiarlo.

$\mathrm{Y}$ en esto, a lo mejor, algunas cosas se tienen que hacer por ley, a veces no, pero hay que hacerlo con urgencia.

Termino diciendo que creo que como país tenemos la obligación, tanto este gobierno como lo tuvo el gobierno anterior y la va a tener el que sigue, de avanzar.

Cuando uno revisa la desconfianza que generaron en Chile ciertas políticas económicas en la década del $70 \mathrm{y}$, sin embargo, vimos como esas desconfianzas con administraciones desatadas y con desabastecimiento fueron superadas y logramos concordar, gobierno y opo- 
sición, un sistema económico que en términos macro responde a un modelo en el cual todos están de acuerdo. Uno dice bueno, increíble, no era menos más fácil ponernos de acuerdo en una política tributaria o en una política expansiva de nuestra economía, pero se logró hacerlo.

Siento que en materia laboral no lo hemos logrado y persisten las desconfianzas. Claro, hay razones para tener desconfianzas cuando uno ve que en año 1981 se dijo que vamos a hacer un sistema de indemnización donde en Chile es la que pacta el trabajador con el empleador. Y si no pactan nada, se aplica el sistema de 30 días que es la última remuneración.

Naturalmente que actitudes como esas generan desconfianzas. Obviamente que hay necesidades, pero así como con la fuerza que uno puede tener hoy día para condenar prácticas de ese tipo, también tenemos que poner de nuestra parte para superar esas desconfianzas. Y yo estoy seguro que eso se puede hacer y en beneficio de ambas partes de la relación laboral. Y estoy convencido que hay espacios desde ya para seguir avanzando.

No creo que haya que inmovilizar cualquier acuerdo ni condicionar todos los acuerdos a un punto. Creo que hoy día si ya hay materias que están pidiendo las partes en las que se puede avanzar, sin perjuicio de las más difíciles, las que generan más desconfianza, podamos verlas simultáneamente.

Muchas gracias.

\section{RONDA DE PREGUNTAS Y RESPUESTAS DE LOS PANELISTAS}

OSVALDO ANDRADE: El primer papelito que me llega no es una pregunta, más bien es una observación afirmación, así es que solo me voy a limitar a leerla.

Dice: es interesante descubrir después de largos años que en el Código del Trabajo chileno prime el principio pro empleador. El empleo que se ha alcanzado no lo encuentra importante. Señor Andrade, pregúntele al señor Zapatero y a los otros países. ¿Y ustedes qué hicieron? Nosotros tuvimos un terremoto.

No me pregunta nada, así es que no le voy a responder. Lo que sí le puedo decir es que no voy a preguntarle al señor Zapatero, no creo que esté en condiciones de responder.

- Pregunta: ¿Cuántas leyes laborales se dictaron cuando usted fue ministro de Trabajo?

- Respuesta: 53 leyes laborales. Los Tribunales del Trabajo, la reforma previsional, el feriado dominical para las trabajadoras de casas particulares puertas adentro, el estatuto para el futbolista profesional que terminó con los contratos de servilleta.

Pero, en mi opinión faltó lo más importante, el proyecto de negociación colectiva y la sindicalización. Eso lo asumo como un déficit. Me habría gustado hacer algo en ese tema.

Pero ni le cuento como recibimos al país hace 20 años.

¿Por qué no hay cambios en el Código del Trabajo en lo referido a los reemplazos de trabajadores en huelga?

Porque para algunos todavía la negociación colectiva era un funcionamiento del mercado. ¿No ven que en el mercado tienen que operar un productor y nada más? Entonces en el sindicato, ¿cómo se van a juntar los consumidores? Eso afecta al mercado. Es así de simple. 
- Otra pregunta: Un fallo de un tribunal alemán dice que si los sindicatos que negocian no tienen derecho a huelga solo les queda mendigar. ¿Cuándo se eliminará el 384 del Código del Trabajo?

- Respuesta del diputado Andrade: Esta es una pregunta un poco tramposa porque la hace un dirigente de la Fenatrap y hace poco estuvimos en Loncura con esos sindicatos hablando de estas cosas. Pero creo que en mi intervención me referí a este tema. Solamente quiero agregar que me parece, además, un tema superinconducente porque hoy día con el mejoramiento de movilización que hay al interior de las empresas, perfectamente puede ser posible que incluso una empresa que presta un servicio público pueda tener derecho a huelga porque existen los turnos para garantizar el servicio básico. Esto funciona en otras partes también.

- Otra pregunta: señor Andrade, ¿por qué no se retoma el diálogo social con los empresarios como ocurrió al comienzo de los años 90?

- Respuesta del diputado Andrade: Yo no tengo cómo responder a eso. Solo puedo decir lo siguiente. El gran problema que tuvo la transición en Chile, y que ha sido una transición especial desde ese punto de vista, es que se hizo con el ex dictador todavía como comandante en jefe del Ejército. Entonces, se le pidió al mundo del trabajo y a sus organizaciones que prescindieran de buena parte de sus reivindicaciones porque había que garantizar la gobernabilidad. Operó, y los que tienen canas se acordarán, la teoría del cincinato, de estos niños nuevos que llegaron y que ligerito nos van a pedir que volvamos, que vuelvan las Fuerzas Armadas a gobernar porque son los únicos que garantizan estabilidad. Ese acuerdo inicial generó una prescindencia del actor laboral. Y por eso buena parte de las primeras iniciativas no consideraron al actor laboral como parte de esta transición. Esto lo saben los dirigentes sindicales, lo hicieron conscientemente. Fue una contribución al país lo que sucedió y que muchos hicieron de esa necesidad una virtud.

- Otra pregunta: Señor Andrade, se habló recién de que la mujer se ha incorporado muy poco al mundo del trabajo en comparación con América Latina u otros países. Yo quisiera saber por qué el gobierno anterior no avanzó en el proyecto de ley de teletrabajo, si la ex presidenta Michelle Bachelet, en su discurso del 21 de mayo de 2006, dijo que había que estimular el trabajo a distancia de las mujeres y de la jornada parcial.

Se presentó un proyecto que yo ayudé a redactar por los dos senadores de Magallanes, el señor Bianchi, independiente, y el señor socialista Augusto Parra. Ahí quedó ese proyecto y no pasó nada.

El actual gobierno presentó otro proyecto que todavía no se concreta, pero todavía no está en la mitad de su período. El otro gobierno terminó.

Me podría explicar eso usted, por favor.

- Respuesta del diputado Andrade: El proyecto de teletrabajo al que se refiere usted lo presentó el senador Roberto Muñoz Barra, que era de la IX Región, no de Magallanes.

Usted tiene razón, no se activó. Y entre otras cosas, porque de las consultas que se hicieron en esa época las mujeres no estaban interesadas en las jornadas parciales, querían jornadas completas. 
Lo que sentían es que había discriminación que para que la mujer se incorporara al mundo del trabajo tenía que ser en condiciones distintas, ofreciéndose sobre la base de jornadas parciales. recuerdo.

Puede haber sido una pesquisa equivocada, pero esa fue la razón que, al menos, yo

Y respecto al teletrabajo, la opinión que yo tengo es que si queremos avanzar sustancialmente en la incorporación de la mujer al mercado del trabajo no creo que por esa vía pueda ser.

Pero creo que el problema fundamental es deslaborarizar el problema de las salas cuna. Creo que no tiene sentido que el asunto de la sala cuna sea un tema laboral. Yo pienso que Chile está en condiciones de ofrecer un estupendo sistema de servicio de cuidados, especialmente con financiamiento tripartito, con competencia de actores públicos y privados, porque hemos visto que el gran problema de acceso de la mujer al mercado laboral tiene mucho que ver con los empleadores. Si nosotros les ofreciéramos un buen sistema de cuidado de los hijos que no esté vinculado al tema de las 20 o más mujeres en la empresa, daríamos un gran salto en materia de empleabilidad femenina.

- Pregunta de asistente: Perdón señor Andrade, pero no me ha dado respuesta al tema del teletrabajo de la mujer. ¿O acaso el gobierno anterior no creía en el teletrabajo?

- Respuesta de diputado Andrade: Yo tengo temor que el tele trabajo sea finalmente, una forma de maquila. Y, créame, que en el proyecto del senador Bianchi, por lo que yo entiendo que usted ayudó a redactar, en lo que a mí concierne había mucho más indicio de maquila que de trabajo a distancia.

NICOLÁS MONCKEBERG: Nunca se había hablado tanto de sindicalización en Chile, y está bien que así sea, como en los últimos 15 años. Y, sin embargo, la sindicalización se estancó.

Nunca se había hablado tanto de la incorporación de la mujer al mundo del trabajo. $\mathrm{Y}$, sin embargo, no se avanzó.

No estoy hablando del último año, sino que de los últimos 20 años.

Nunca se había hablado tanto de la productividad de la empresa. Y, sin embargo, retrocedió.

Nunca se había hablado de lo importante que es generar empleos en Chile habiendo documentos de balance y de crisis. Y, sin embargo, el promedio de los últimos 20 años, analizando todas las crisis económicas y todos los momentos de bonanza que hubo también, tampoco se ha alcanzado como en el último año.

¡Ah, no, pues -escuché a un ex Presidente decir- que si el empleo que está generando Chile no es nada más ni nada menos que debido al crecimiento de China! Es el rebase natural de las tasas de crecimiento de Chile y como Chile tiene una economía conectada con ellos, le toca algo.

Es bonito ese argumento, pero el ex Presidente reconoce que China estaba creciendo al $8 \%$ cuando Chile crecía al $1 \%$. O sea esta teoría del rebase de las empresas extranjeras es bastante relativa, o apliquémosla con la misma vara en ambos casos. 
Al final, lo que quiero decir con esto es que nosotros tenemos que ir a las causas profundas de las cosas y no hacer de cada una de estas discusiones una suerte de ideología con la cual uno tiene un compromiso de defender sus puntos de vista sin ir al fondo del problema.

A mí me pregunta aquí una persona por qué en Chile solo se legisla para los pobres cuando se debe legislar para la clase media.

Le encuentro razón, dado lo que se ha hecho o a lo que se le ha dado más publicidad en la última agenda social.

Tengo que contarles, por suerte, que la agenda pro crecimiento que se acaba de anunciar ahora, que incluye todas las medidas de impulso competitivo, están pensadas en el grueso de ellas en las pequeñas y medianas empresas. Y yo creo que ahí apuntan al corazón de la clase media si realmente al implementarlo lo hacemos bien.

Me quiero gastar un minuto en tocar este punto porque Osvaldo, ante una pregunta, relataba las leyes más importantes que le tocó promover cuando estuvo en el cargo de ministro del Trabajo. Y, efectivamente, promovió leyes importantes. Pero yo les aseguro que nosotros concurrimos en la aprobación de prácticamente todas ellas. Y concurrimos con colaboración, con ideas, con realismo y con responsabilidad.

Porque era muy fácil decir cuando la presidenta Bachelet subía las pensiones mínimas a $\$ 75$ mil que eran indignas, que ningún chileno puede vivir con esa cantidad, que la pensión mínima debía ser, mínimo, de $\$ 130$ mil. Pero nosotros concurrimos a aprobar ese punto que propuso el gobierno, que es distinto a lo que ahora vemos. Porque todos quisiéramos un postnatal sin tope. Sin embargo, la Concertación no está por romper todos los cánones constitucionales y rechaza el tope.

O sea, hoy día es el parlamento el que le va a decir al gobierno qué hacer. Queremos que al parlamento el gobierno le proponga un salario mínimo de $\$ 200$ mil, pero ¿sabe que más?, mejor se lo subo a $\$ 500$ mil. Y faltan seis meses para las elecciones. Esa no es la forma seria, a mi juicio, de cómo deben funcionar estas instituciones.

La tentación en política de hacer populismo siempre existe, tanto por parte del gobierno como de la oposición. Pero yo creo que este último año se ha roto un poco el cambio. El postnatal que hoy día existe en Chile es lejos el más elitista y menos focalizado de todos los subsidios. Recuerden que el postnatal no lo paga la Isapre, sino que un subsidio estatal y, por lo tanto, veamos adónde llega ese aporte estatal.

El 70\% de la plata que el Estado pone para el postnatal se va al quintil más rico. ¿Por qué eso? ¿Cómo podemos haber pasado tanto tiempo con una suerte de vacuna, en que nos daba lo mismo que con la plata con la que podríamos financiar un postnatal a una persona que va con su guagüita a la feria a trabajar? Pero nos quedamos tranquilos con el postnatal de una persona que gana un salario mayor.

Lo que quiero decir, para terminar, es que recuperemos en Chile, aunque a veces duela porque yo sé que hay personas que la pueden estar pasando mal, con alto nivel de endeudamiento, el sentido de la urgencia. Chile es un país con extrema pobreza, con muchas carencias que requiere reivindicar lo que dijo Juan Pablo Segundo, que los pobres no pueden esperar.

Por lo tanto, cuando se dice que vamos a tener que esperar tres meses más en el postnatal, porque a la Concertación se le ocurrió votar en contra del tope, ese es francamente un camino equivocado. 
Se puede discutir respecto del monto, como se discutió en el gobierno anterior, pero yo no puedo aceptar que una ley social se haya estancado, como la ley de postnatal.

- Pregunta de asistente: ¿Qué pasa hoy día con la fusión de los sindicatos que se ve entorpecida con algunos plazos que se estipulan a nivel de gobierno, con respecto a la intervención, por ejemplo, de la Dirección del Trabajo? Hoy, sucede que hay que dictarle palabra por palabra al funcionario que va a tomar nota de una acusación o, en este caso, de una situación engorrosa que se vive en algunas empresas, lo que significa que el tema se trata con menos fiscalización.

Hoy en día lo que me preocupa, por ejemplo, es que una de las cosas que más se da tiene que ver con los despidos con causa injustificada o con error del artículo en que se demoren más de tres meses en los procesos que se han saneado. Eso, al resto de los trabajadores les implica que, definitivamente, son los sindicatos los que estamos haciendo mal la pega ante esa subsanación de esa situación para el trabajador.

- Respuesta del diputado Monckeberg: Bueno, no puedo estar más de acuerdo contigo que esta es una situación preocupante.

Tenemos que ir al fondo y analizar por qué en Chile no está de moda sindicalizarse. Puede ser un poco duro decirlo, pero me baso en las estadísticas. ¿Por qué han caído las tasas de sindicalización?

Y digo, no tengo ninguna duda, que tiene que haber prácticas antisindicales. Y no digamos que en todos los países las hay. No, pues. Entonces veamos cómo fiscalizamos que ellas sean sancionadas drásticamente para terminar con esto.

Yo les pido que seamos capaces de denunciar estas normas que hoy están entorpeciendo una buena labor de buenos dirigentes sindicales. El otro día yo hablaba con el presidente de la CUT sobre la forma en como funcionan los famosos sindicatos del día después. Por supuesto, cuando fueron concebidos estos tenían su lógica. Y la lógica era que el trabajador que estaba formando un sindicato requería de algún tipo de protección de fuero.

Pero todos sabemos que eso ha derivado, en algunos casos, en un uso fraudulento de esa protección.

Yo creo que hoy día, de verdad, y comparto tu punto de vista, hay normas que arreglar y corregir. Primero, para fiscalizar mucho mejor y que terminen las prácticas antisindicales. Segundo, para operar en la fiscalización en forma mucho más directa en beneficio final del trabajador.

BRUNO BARANDA: Quisiera hablar, antes de responder, de unas cuatro cositas para que no queden improcedentemente en el aire.

Los trabajos que se han creado en estos últimos 12 meses, sin entrar a discutir si son 480 mil o no, si son varias horas a la semana o jornadas completas, se trata de la medición que existe y que es comparable con la medición de hace ya un año. Debiéramos estar contentos en la medida en que somos capaces de crear muchos empleos. Que se necesitan más, por supuesto que sí y que sean mejores, y Dios quiera que así sea.

Qué duda cabe. 
Pero, precisamente, los mismos antecedentes del Instituto Nacional de Estadísticas (INE) que nos entrega los índices de empleo, nos advierte que el 53\% de los creados sí son empleos asalariados, con previsión y salud, y no precarios como equivocadamente se señaló.

En segundo lugar, el resto de los empleos no significa que sean precarios. Hay mucha gente independiente, autoempleo, personas que son emprendedores pequeños o empresarios individuales que, la verdad, pueden estar mucho mejor que los empleados asalariados.

Por eso hay que tener prudencia al descalificar el esfuerzo enorme de todas estas personas que representan más del 3\% de la caída de la tasa de cesantía en nuestro país, y que son miles y miles de chilenos y chilenas que, gracias a Dios, salieron de la cesantía.

El gobierno va a estar tremenda y completamente preocupado y angustiado en la medida en que haya una familia de algún trabajador que esté sufriendo el flagelo de la cesantía.

Pero analizar la creación de empleos calificándolos como precarios con el propósito de corroer, de deteriorar este esfuerzo magnífico que, en parte importante, se debe a las políticas públicas impulsadas por el presidente Piñera y el gobierno de la Coalición por el Cambio, es simplemente injusto y equivocado.

No es casual que crezcamos hoy día a tasas del 6\% ni que la productividad, después de tantos años que venía cayendo, y negativamente, haya tomado tasas positivas. Esperamos que supere el $1 \%$ este año.

No es casual, tampoco, que la tasa de cesantía haya caído en más de un 3\% en los últimos dos años.

En consecuencia, no creo ni quiero, ni tampoco tenemos que sobregirarnos en advertirlo y ufanarnos de ello, sino estar contentos, satisfechos y saber que hay mucho por trabajar.

Pero la verdad es que resulta tremendamente injusto desvalorizar, deteriorar o, precisamente, generar dudas e incertidumbres respecto de esa realidad.

Enseguida, tampoco creo que sea justo señalar que el gobierno no quiso extender los beneficios del teletrabajo al sector público, porque yo mismo le di la respuesta en la comisión de la Cámara al diputado Andrade, que propuso esta ampliación, que no nos correspondía a nosotros pronunciarnos producto de que las relaciones laborales no se centran en el gobierno, no particularmente en nuestro gobierno, sino que por lo menos por 20 años las lidera, respecto del sector público, el Ministerio de Hacienda.

Sin perjuicio de eso, decimos que es interesante, que no debiera haber inconvenientes, pero que evidentemente no nos corresponde a nosotros definir, y aún así el gobierno está disponible para avanzar en eso.

Esas fueron las palabras con precisión a objeto de no equivocarse injustamente.

Y, precisamente, me cuelgo yo de la explicación que ha dado acá el diputado Monckeberg referido al postnatal. La verdad es que por primera vez en 20 años que en el Senado se aprueba un proyecto de ley que tenía solo de positivo, porque podrán ser más mujeres trabajadoras las que se incorporen al beneficio del postnatal, que podrá ser el límite del subsidio sobre las 30 UF.

Miren, yo creo que hay que darle todo el beneficio de inventario y, efectivamente, todo eso puede ser. Lamentablemente, el gasto público es limitado y hay que establecer, en consecuencia, un parámetro. Este era un paso positivísimo para todas las mujeres en cuanto a la protección de la maternidad, pero lo que hizo la Concertación, irresponsablemente en 
consecuencia, al aprobar un gasto público que solo depende del gobierno es detener la posibilidad de que del orden de las 100 mil mujeres, que hoy día no están cubiertas por este proyecto de ley, se incorporen.

Además, aquellas que al momento de dictarse esta ley, en el evento que se hubiese dictado, estén en cualquier estadio de su embarazo, prenatal, postnatal, recién embarazada, etc., la verdad es que van a carecer de este beneficio.

En seguida, el límite tiene un sentido de focalización del gasto público a los sectores no solo más vulnerables, sino medios y medios bajos. El 83\% de las mujeres en Chile gana menos de $\$ 650$ mil, en consecuencia, lo que ha propuesto el Presidente de la República es, precisamente, concentrarse en ese límite. No es que las que tengan remuneraciones superiores a ese límite vayan a quedar excluidas. Ese es el sentido al límite al subsidio.

Enseguida, a propósito de que el 55\% de los fondos que hoy el Estado destina, es la herencia que recibimos nosotros, es usufructuado por el $20 \%$ de las mujeres con remuneraciones más altas en el mercado laboral. Y el 20\%, en contraste con las mujeres con remuneraciones más bajas solo accede al 5\% de los fondos que el Estado destina a la protección a la maternidad.

En consecuencia, aparece del todo lógico, racional y sensato querer luchar en contra de esta inequitativa ecuación para tratar de invertir más recursos en los sectores medios o medios bajos, sin dejar que aquellas que ganan más tengan también este beneficio. Única y exclusivamente se trataba de poner un límite.

Pero desde el momento en que la Concertación aprueba un proyecto de ley poniendo el gasto público, que solo es competencia del Presidente de la República, no es precisamente el gobierno ni los parlamentarios de la Coalición por el Cambio quienes van a enviar este proyecto a su discusión o análisis constitucional. Creo que es, precisamente, la Concertación, a nuestro juicio en un acto difícil de entender, la que ha perjudicado a un gran número de trabajadoras.

- Pregunta de asistente ¿qué entiende el gobierno del presidente Piñera por trabajos de calidad? Y pide mencionar algunas características de este concepto.

- Respuesta del subsecretario Baranda: Pues muy bien, el trabajo de calidad significa empujar a tener remuneraciones de tal nivel para que ese trabajador y su familia puedan tener una calidad de vida suficiente, como la que a cualquiera de nosotros nos gustaría o quisiéramos. de salud.

En segundo lugar, que tengan previsión, seguridad social y seguridad laboral, además

En tercer lugar, que se respeten los derechos laborales, que esa relación y vínculo laboral respete la jornada, sus límites y que los descansos entre semanas se cumplan.

Hay una serie de cualidades con las cuales nosotros estamos redefiniendo un esfuerzo, de la difusión y expansión de las buenas prácticas laborales y, precisamente, recoge muchas de estas definiciones que tenemos sobre el trabajo de calidad.

- Pregunta de Francisco Manríquez, vicepresidente de la Federación de Trabajadores de Obras Sanitarias: El mundo laboral no escuchó el 21 de mayo ninguna medida real que cambie la realidad del plan laboral de los años 80 . 
- Respuesta del subsecretario Baranda: La verdad es que nosotros recogimos el país que todos conocen, con el estadio a nivel legislativo y, sobre todo, el sector público que conocen. Y lo que estamos haciendo es empujar para cambiar muchas cosas que dicen relación con la posibilidad de acceso a nuevos y mejores empleos.

Y eso está en el corazón del programa del presidente Piñera. Cuando él afirma crear un millón de nuevos y buenos empleos se refiere a esta parte importante. Y para eso debemos mover los servicios y los instrumentos que el Estado tiene para que estén de nuevo al servicio de los trabajadores, al servicio de una mejor relación laboral colaborativa y constructiva.

En segundo lugar, hay una serie de medidas que de una u otra forma golpean también a los trabajadores del país, tales como el Sernac financiero, del esfuerzo que nos presentó hace unos días el ministro de Economía junto al Presidente de la República y que dicen relación con el impulso competitivo; también hay una serie de medidas del SENCE que hemos tomado, pues por primera vez en regiones se están definiendo los programas para capacitarse. También por primera vez el trabajador va a poder escoger libremente el lugar donde capacitarse en un programa especial que ya está implementándose. Hay también una bonificación para los pequeños y medianos empresarios que antes no tenían acceso al SENCE.

En suma, estamos caminando, solo para poner algunos ejemplos, para avanzar fuertemente.

Estos proyectos de ley que estamos presentando, a propósito del postnatal, dicen relación con esta agenda del gobierno y la respuesta que hemos dado al llamado multirrut.

Bueno, son respuestas que pueden satisfacer más o menos, pero la verdad es que es la respuesta que el gobierno ha dado a los requerimientos y clamor de los trabajadores en los últimos 21 años en el país.

No habíamos conocido una propuesta anterior de ninguno de los gobiernos de la Concertación y por eso el gobierno de la Coalición por el Cambio, viene a proponer una respuesta que da estas herramientas sustanciosas de negociación colectiva frente a esta multiplicidad de compañías con ciertas características objetivas. Ni siquiera se exige subjetivamente que esa subdivisión de empresas sea con el destino o, precisamente, sea efectuada para deteriorar los derechos laborales.

En consecuencia, de nuevo, al igual que en las referencias que hice al proyecto de postnatal, podrá ser mejorada. Por cierto que podrá serlo.

Pero lo que hace difícil desarrollar, trabajar y establecer las confianzas es esta actitud de destrozo de las iniciativas que vienen en beneficio de los trabajadores del país, tales como la negociación colectiva frente a ciertas características objetivas frente a multiplicidad de RUT

¿Se fijan?

Ahí hay una respuesta efectiva, por lo demás, a propósito del diálogo social que fue impresionantemente discutida por parlamentarios de gobierno y de oposición, por muchos dirigentes de sindicatos de base o asesores de las tres centrales sindicales, muchas horas de trabajo con la participación, también de profesores y analistas de distintos criterios laboralistas. O sea, también de nuevo llama la atención.

- Pregunta Cristián Rivero, dirigente de los subcontratados del retail: ¿Por qué no se termina con la facultad de la patronal para externalizar con más de un contratista una misma labor? 
- Respuesta del subsecretario Baranda: Pues bien, la ley permite que las empresas subcontraten ciertos servicios dadas ciertas condiciones o características y, justamente, a propósito de una serie de experiencias de los últimos días es que vamos a entrar a fiscalizar con mayor profundidad a través de la Dirección del Trabajo si es que, efectivamente, la ley de subcontratación se está aplicando y en la medida que están los espacios que la propia ley lo indica. Esa es una iniciativa de nuestro gobierno y en los próximos días vamos a iniciar la labor al respecto.

- Pregunta Jaime Salazar, sindicado de profesionales de Aguas Andinas: ¿El nuevo trato laboral considera un piso para los trabajadores?

- Respuesta del subsecretario Baranda: ¿Qué significa el nuevo trato laboral? La verdad es que puede tener otro nombre, pero lo que queremos decir es que con esto vamos a concentrar una parte importante del gobierno del presidente Piñera para subir y mejorar la calidad de vida de los trabajadores y de las relaciones laborales.

La siguiente pregunta se refiere a la modificación a la legislación que se está estudiando, ¿incluye modificaciones al Código del Trabajo en aspectos tales como arbitraje y costo a propósito de los arbitrajes obligatorios en la negociación colectiva?

Por cierto, ya estamos en la etapa final de un proyecto de ley que estamos barajando desde hace un tiempo, en el cual hemos incorporado a la discusión a bastante gente en que, efectivamente, le queremos hincar el diente al cuerpo de arbitrajes, a la institucionalidad del sistema y del procedimiento porque compartimos con los trabajadores de Aguas Andinas lo vergonzoso que es que aquellos que solo tengan recursos, cuantiosos por lo demás, puedan acceder en una primera instancia a este centro de arbitrajes, sin desmerecer por ningún motivo ni hacer un juicio de valor en la institucionalidad que existe después de 20 años de la Concertación.

Queremos, precisamente, modificarla para que sea un instrumento al servicio de todos los trabajadores y no solo para aquellos que sean capaces de reunir y juntar $\$ 20$ millones para poder recurrir a él en primera o en segunda instancia.

Ya tomamos la iniciativa de trabajar en esa línea porque tiene que transformarse en un servicio y en un instrumento que dice relación, justamente, con el nuevo trato y cómo queremos nosotros colaborar a que esa herramienta del arbitraje obligatorio se transforme en una instancia útil, colaborativa para las relaciones laborales en función de diferencias en ciertas negociaciones colectivas.

- Pregunta: ¿Usted condena que el pago de remuneraciones mensuales de \$175 mil sirva para que un hombre pueda vivir?

- Respuesta del subsecretario Baranda: Entiendo que es la insuficiencia. Seguramente muchos de nosotros vamos a coincidir en que la remuneración de esa cantidad de dinero puede ser insuficiente.

Estamos empujando con esto que les he dicho un aumento, no solo con las políticas públicas y el crecimiento que, obviamente, son una herramienta fundamental para que haya más y mejor empleo. El que las remuneraciones estén creciendo, el que la productividad esté creciendo, etc., obviamente que son una herramienta fundamental para mejorar la calidad del empleo y sus remuneraciones. 
Y, en segundo lugar, para superar la pobreza, pero no es suficiente, a juicio nuestro, y por eso es que estamos transformando instituciones, tales como el SENCE, para que realmente sirvan para una mejor y mayor empleabilidad en la medida en que haya mayores competencias laborales a través de las certificaciones o de las capacitaciones. También nos va a permitir que los trabajadores puedan acceder a mejores remuneraciones a través de las fiscalizaciones en la medida que haya más incumplimientos en las cotizaciones. Esos son todos elementos que coayudan y complementariamente se está trabajando en el ingreso ético familiar que viene a ayudar como una mano colaborativa a aquellas familias que están en escasez de recursos o en una mayor vulnerabilidad.

- Pregunta: Este es un diálogo de sordos. No se ve nada concreto. ¿Hasta cuándo vamos a esperar? Chile no puede más.

- Respuesta del subsecretario Baranda: La verdad es que a nuestro juicio no es un diálogo de sordos. Yo les expliqué dos proyectos de ley en los cuales hemos incorporado a mucha gente en la discusión, gente de gobierno y de oposición, de distintos criterios y posiciones o distintos sectores.

En segundo lugar, el esfuerzo que hemos hecho nosotros con la instalación de la Comisión Asesora Presidencial de Seguridad Laboral también fue un trabajo inédito en el país.

Recibimos a todos aquellos que quisieran reunirse con la Comisión, les tomamos la palabra, sean trabajadores o dirigentes. Se convocó a todas las centrales sindicales, a muchos parlamentarios que concurrieron.

Algunos de ellos se negaron y se excluyeron por propia voluntad. Pero ese fue un esfuerzo inédito para recibir opiniones de las fuerzas activas de la sociedad.

Bueno, ahí hay una muestra palpable de voluntad de diálogo y de trabajo mancomunado con la sociedad. Y hay muchas otras instancias en donde nosotros tenemos cifradas esperanzas de que se llegue a acuerdos.

En la mesa agrícola, por ejemplo, se está discutiendo en su etapa final un notable acuerdo que va a dar forma a un estatuto del trabajador agrícola y de los temporeros, en que esas labores se van a regular en profundidad. Es un trabajo en donde se ha reunido del orden de los 40 o 50 dirigentes sindicales, y a dirigentes de los empleadores de las distintas organizaciones agrícolas.

Y a veces cuando se reclama más diálogo es que la disponibilidad para el diálogo está en la palabra, pero no en la práctica.

Eso es un ejemplo palpable como otros que hemos visto, como otros en donde se ha invitado al diálogo y donde se han producido los frutos de proponer de común acuerdo entre empleadores y trabajadores algunas regulaciones. Pues bien, el brazo político, la mano ideológica viene a romper y a torcer esa voluntad para perjudicar derechamente los derechos de los trabajadores.

Si hoy tuviésemos un proyecto en trámite con esas características, producto del empuje de todos los dirigentes políticos de los distintos partidos, especialmente de la Concertación, naturalmente que los trabajadores agrícolas estarían ad portas de tener un estatuto que regulara en mejor medida la relación laboral.

La invitación al diálogo, entonces, tiene que ser genuina, del corazón, intensa. El pro- 
pio diputado Andrade ha sido invitado por la ministra Matthei a participar en una mesa de equidad y desarrollo. Pues bien, por la prensa nosotros nos hemos enterado que algunos se negaron a participar y no se sentían convocados.

En consecuencia, es superimportante que al diálogo colaboremos genuinamente para que sea fructífero y saquemos realmente resultados positivos en beneficio de los trabajadores y de los empleadores, porque yo soy de aquellos que siguen convencidos de que los grados de conflictividad y de confianza son menores y que muchas veces son creados artificialmente por dirigentes que reclaman ciertas cosas.

Y hemos dado testimonio en el Ministerio del Trabajo en este año de gobierno de cómo nos hemos involucrado en forma profunda y seria, y con mucho corazón, en la defensa de los intereses de los trabajadores.

Pero yo creo que no pasa en la mayoría de las relaciones laborales que son extremos de desconfianza, como a veces se nos presenta o como muchas veces sí se empuja para que generen y se desarrollen en teoría.

HÉCTOR HUMERES: Bien, con esta última intervención ponemos fin al presente Foro, agreadeciéndole desde ya a todos nuestros panelistas por sus destacadas e interesantes intervenciones, y a todos ustedes por su gentil concurrencia a este debate, dejándolos cordialmente invitados desde ya a participar en las futuras actividades que sobre esta disciplina efectuará nuestra Departamento. Muchas gracias. 